\title{
PREPARATION, PHYSICAL CHARACTERIZATION, AND PHARMACOKINETIC STUDY OF DOCETAXEL NANOCRYSTALS
}

\section{ARVIND GANNIMITTA ${ }^{1 *}$, PRATHIMA SRINIVAS ${ }^{2}$, VENKATESHWAR REDDY A ${ }^{3}$, PEDIREDDI SOBHITA RANI ${ }^{4}$}

${ }^{1}$ Aurobindo Pharma Pvt., Ltd., Hyderabad, Telangana, India. ${ }^{2}$ Shantha Biotechnics Private Limited, Hyderabad, Telangana, India. ${ }^{3}$ Anwarul Uloom College of Pharmacy, Hyderabad, Telangana, India. ${ }^{4}$ Vijaya College of Pharmacy, Munaganur, Hayathnagar, Hyderabad, Telangana, India. Email: nandus4u1980@gmail.com

Received: February 28 2019, Revised and Accepted: April 302019

ABSTRACT

Objective: The main objective of this study was to prepare and evaluate the nanocrystal formulation of docetaxel.

Methods: Docetaxel nanocrystals were formulated to improve the water solubility. Docetaxel nanocrystals were prepared by nanoprecipitation method using Tween 80, egg lecithin, and povidone C-12 as stabilizers and poly(lactic-co-glycolic acid) (PLGA) as polymer in acceptable limits. A total of 16 formulations were prepared by changing stabilizer and polymer ratios. The prepared nanocrystals were characterized by particle size, zeta potential, crystalline structure, surface morphology, assay, saturation solubility, and in vitro drug release.

Results: Based on particle size, polydispersity index, and zeta potential data, four formulations were optimized. The formulation containing Tween 80 as stabilizer has shown lowest particle size and better drug release than the formulations containing egg lecithin and povidone C-12 as stabilizers. The formulation containing Tween 80 and PLGA has shown still lower sized particles than the Tween 80 alone and exhibited prolonged sustained drug release. The release kinetics of formulations containing Tween 80 and PLGA followed zero-order release kinetics and formulations containing egg lecithin and povidone C-12 followed Higuchi diffusion (non-Fickian).

Conclusion: From the study, we concluded that as the type and concentration of stabilizer changed the size and shape of the crystals were also changed and the formulations showed sustained drug release with non-Fickian diffusion.

Keywords: Docetaxel, Nanocrystals, Tween 80, Egg lecithin, Povidone C-12, Poly(lactic-co-glycolic acid).

(C) 2019 The Authors. Published by Innovare Academic Sciences Pvt Ltd. This is an open access article under the CC BY license (http://creativecommons. org/licenses/by/4. 0/) DOI: http://dx.doi.org/10.22159/ajpcr.2019.v12i6.32856

\section{INTRODUCTION}

Cancer is the main cause of death worldwide. Nanotechnology has a great approach to have a revolutionary impact on cancer diagnosis and therapy [1]. The use of different formulation techniques such as inclusion complexes, emulsions, microemulsions, micelles, liquid solids, liposomes, and microspheres was prevented due to poor physical stability, difficulty in scale-up, and inability to achieve high drug-loading problems [2]. Drug delivery through nanoparticles presents novel therapeutic opportunities for drugs that were previously unsuited to traditional oral or injectable drug formulations, allowing drugs to be delivered efficaciously while reducing side effects and shows better patient compliance [3].

Docetaxel is a semi-synthetic derivative comes under taxoid family [4]. It is an analog of paclitaxel which is extracted from the European yew tree (Taxus baccata L.). Being a microtubule-stabilizing agent, it inhibits microtubule disassembly causing inhibition of cell division and eventual cell death. Docetaxel is used to treat a number of cancers such as breast, ovarian, lung, head, and neck cancer. It shows more affinity (1.9-fold) for microtubules when compared with paclitaxel [5-8]. Despite these advantages, clinical use of docetaxel is still limited due to its low water solubility. It is presently marketed as TAXOTERE. RTM injection concentrate, due to its poor water solubility docetaxel, is given in a vehicle containing high concentration of Tween 80 and the injection needs to be diluted with $13 \%$ ethanol in water for injection. The presence of high concentrations of Tween 80 and ethanol causes severe adverse effects like several hypersensitivity reactions and it also shows incompatibility with common PVC intravenous administration sets $[9,10]$.
It has been reported that the toxicity of DTX is mainly based on the formulation technique. As a result, the current investigations are focused on different formulation techniques like nanotechnology. Recently, various nanonization strategies have emerged to improve the dissolution rates and solubility of insoluble drugs, for example, polymeric nanomicelles, nanoemulsions, nanostructured lipid carriers, and nanocrystals, whereas in nanocrystal technology which can be applied to all poorly soluble drugs is the simplest and practical approach because all these drugs could be directly disintegrated into nanosizing particles [11-13]. In nanosuspensions, drugs can exist in two forms: Crystalline state and amorphous state: When drug particles exist in the form of crystalline state, they are called as nanocrystals. Nanocrystals, a carrier-free colloidal drug delivery system, consist essentially of pure drug crystals and a minimum amount of surfactants required for stabilization and have been applied to tackle the formulation issue of poorly soluble drugs. With particle size in nanometer range and enormous particle surface area, nanocrystals can increase the dissolution velocity and saturation solubility of the number of insoluble drugs, therefore, improving their bioavailability and biological effects [14-19].

Nanocrystals can be administered through various routes such as oral [20], parenteral [21], ocular [22], pulmonary [23], and dermal [24], as well as for targeted delivery [25]. Nanocrystals can be produced by bottom-up (antisolvent precipitation) and top-down (media milling, high-pressure homogenization, etc.) technologies or combination technologies and chemical synthesis [26]. Nanoprecipitation comes under bottom-up technique in which a poorly water-soluble drug is dissolved in an organic medium, which is water miscible and a pouring of this solution into a non-solvent, will cause precipitation of finely dispersed drug nanocrystals. The stabilizers which are used in the 
formulation adsorbed on the formed drug particles to inhibit crystal growth $[27,28]$.

The main objective of this study was to prepare and evaluate the docetaxel nanocrystals and study the effect of various stabilizers on the physicochemical properties and in vitro release studies. Characterization of DTX nanocrystals was carried out by different techniques such as Fourier-transform infrared spectroscopy (FTIR), particle size analysis, zeta potential, scanning electron microscopy (SEM), and drug release profile.

\section{MATERIALS AND METHODS}

Docetaxel was obtained from Ningbo Samreal Chemical Co., Ltd., China, povidone from BASF, polysorbate 80 from Seppic, France, and egg lecithin from Doosan Corporation, Korea. Poly(lactic-co-glycolic acid) (PLGA) was obtained from Purac Biochem, Netherlands. All the ingredients were analytical grade. The laboratory grade chemicals used for the work are ethanol, n-methylpyrrolidone, propylene glycol, sodium hydroxide, and potassium dihydrogen phosphate purchased from Merk Chemicals, Mumbai.

\section{Preformulation study}

Construction of a calibration curve by ultraviolet (UV)

About $1 \mathrm{mg} / \mathrm{ml}$ of docetaxel stock solution was prepared using isopropyl alcohol (IPA) and water (50:50) as mixed solvent and further dilutions were made with the same solvent. To a series of $10 \mathrm{ml}$ volumetric flasks, aliquots of standard solutions were taken and the volume was made up to the mark. Moreover, the absorbance of all the solutions was

\section{calibration plot of docetaxel in 50\% IPA and 50\% 7.4 PBS}

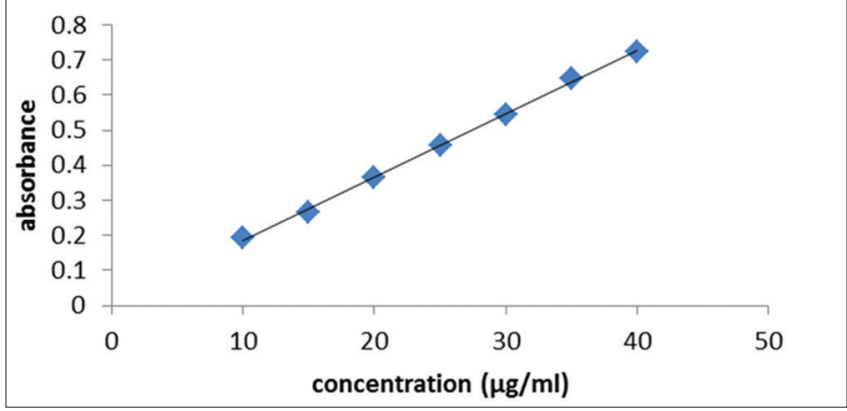

Fig. 1: Standard graph of docetaxel in isopropyl alcohol and phosphate buffer of pH 7.4 (50:50) measured at $231 \mathrm{~nm}$. A graph was plotted by taking absorbance on $\mathrm{Y}$-axis and concentration on $\mathrm{X}$-axis.

\section{Drug excipient compatibility study}

Compatibility studies are important to select suitable excipients for any pharmaceutical formulation. Therefore, in the present work, a study was carried out using FT-IR to find out if there is any possible chemical interaction of drug with excipients used in the formulation.

The FTIR spectra of different nanocrystals were carried out by potassium bromide disc method using Tensor 27 FTIR spectrophotometer (Bruker Optics, Germany) in the region of $4000-600 \mathrm{~cm}^{-1}$.

\section{Determination of partition coefficient}

A partition coefficient is the ratio of concentrations of a compound in a mixture of two immiscible phases at equilibrium. These coefficients are a measure of the difference in solubility of the compound in two phases, i.e., hydrophilic and hydrophobic. Hence, the partition coefficient is measured whether the chemical substance is hydrophilic or hydrophobic and partition coefficient is used to estimate the distribution of drugs within the body. Hydrophilic drugs (low octanol/ water partition coefficients) preferentially are found in hydrophilic compartments such as blood serum, whereas hydrophobic drugs with high octanol/water partition coefficients are preferentially distributed to hydrophobic compartments such as lipid bilayers of cells.

The partition coefficient of docetaxel was determined in octanol/water, n-hexane/water, oleyl alcohol/water, and dichloromethane/water systems at room temperature. Equal volume of organic phase and aqueous phase was taken in a glass stopper graduated tube and $25 \mathrm{mg}$ of drug was added. The mixture was then shaken using mechanical shaker periodically at room temperature for $24 \mathrm{~h}$. Then, the mixture was transferred to a separating funnel and allowed to equilibrate for $6 \mathrm{~h}$. The aqueous and organic phase was separated and filtered through membrane filter and drug content in each phase was analyzed by UVvisible spectrophotometer. The partition coefficient was calculated using the below formula.

$$
\mathrm{Ko} / \mathrm{w}=\mathrm{Co} / \mathrm{Cw}
$$

\section{Preparation of docetaxel nanocrystals}

Docetaxel nanocrystals were prepared by nanoprecipitation method using ethanol and n-methylpyrrolidone as solvents; propylene glycol as an antisolvent; Tween 80 , povidone $\mathrm{C}-12$, and egg lecithin as stabilizers; and PLGA as polymer. Sixteen formulations have been developed by using different surfactants at different concentrations as shown

Table 1: Formulation of docetaxel nanocrystals

\begin{tabular}{|c|c|c|c|c|c|}
\hline Stabilizer & Formulation & $\begin{array}{l}\text { Volume of } \\
\text { solvent }(\mathrm{mL})\end{array}$ & $\begin{array}{l}\text { Volume of } \\
\text { antisolvent }(\mathrm{mL})\end{array}$ & $\begin{array}{l}\text { Quantity of Tween } \\
80 \text { (or) PLGA (mg) }\end{array}$ & Molar ratio \\
\hline \multirow[t]{4}{*}{ Tween 80} & F1 & 1 & 1 & 30.392 & $1: 0.5$ \\
\hline & F2 & 1 & 1 & 60.784 & $1: 1$ \\
\hline & F3 & 1 & 1 & 182.352 & $1: 3$ \\
\hline & F4 & 1 & 1 & 364.704 & $1: 6$ \\
\hline \multirow[t]{4}{*}{ Egg lecithin } & F5 & 1 & 1 & 18.328 & $1: 0.5$ \\
\hline & F6 & 1 & 1 & 36.656 & $1: 1$ \\
\hline & F7 & 1 & 1 & 109.968 & $1: 3$ \\
\hline & F8 & 1 & 1 & 219.936 & $1: 6$ \\
\hline \multirow[t]{4}{*}{ Povidone } & F9 & 1 & 1 & 58 & $1: 0.5$ \\
\hline & F10 & 1 & 1 & 116 & $1: 1$ \\
\hline & F11 & 1 & 1 & 348 & $1: 3$ \\
\hline & F12 & 1 & 1 & 696 & $1: 6$ \\
\hline \multirow[t]{4}{*}{ Tween 80 and PLGA } & F13 & 4 & 2 & 40 & 1:1:0.001 \\
\hline & F14 & 4 & 2 & 80 & 1:1:0.003 \\
\hline & F15 & 4 & 2 & 160 & 1:1:0.006 \\
\hline & F16 & 4 & 2 & 320 & $1: 1: 0.012$ \\
\hline
\end{tabular}

PLGA: Poly (lactic-co-glycolic acid) 
in Table 1. From the results the optimized formulations have been identified as shown in Table 2.

In this method, the drug was dissolved in ethanol. After that, the drug dissolved stabilizer solution was added. This solution was mixed using

Table 2: Optimized formulation of docetaxel nanocrystals

\begin{tabular}{llll}
\hline $\begin{array}{l}\text { Serial } \\
\text { number }\end{array}$ & Stabilizer & $\begin{array}{l}\text { Optmized } \\
\text { molar ratio }\end{array}$ & $\begin{array}{l}\text { Formulation } \\
\text { code }\end{array}$ \\
\hline 1 & Tween 80 & $1: 1$ & $\mathrm{~F} 2$ \\
2 & Egg lecithin & $1: 3$ & $\mathrm{~F} 3$ \\
3 & Povidone C-12 & $1: 1$ & $\mathrm{~F} 10$ \\
4 & Tween 80 and PLGA & $1: 1: 0.001$ & $\mathrm{~F} 13$ \\
\hline
\end{tabular}

PLGA: Poly (lactic-co-glycolic acid) cyclomixer at $150 \mathrm{rpm}$. To this solution, an antisolvent, i.e., propylene glycol was added and mixed. The resulting formulation was kept a side for $24 \mathrm{~h}$ at room temperature [29-31].

\section{Physical characterization of docetaxel nanocrystals}

Microscopic evaluation

A drop of the formulation was added in the middle of a clean slide and placed a coverslip. Then, place the prepared slide onto the stage of the microscope. Observe the shape of crystals under microscope using $\times 40$ eyepiece and capture the images using Motic image software.

\section{Particle size and zeta potential}

The average diameter and polydispersity index of the nanocrystals were determined by particle size analyzer (Horiba, nanopartica sz-100

Table 3: Partition coefficient of docetaxel in different solvent systems

\begin{tabular}{|c|c|c|c|c|c|c|}
\hline Solvent system & Solvent & Diluted with & Concentration $(\mu \mathrm{g} / \mathrm{mL})$ & Concentration (mg/mL) & $\mathbf{p}$ & $\log p$ \\
\hline \multirow[t]{2}{*}{ Octanol-water } & Octanol & IPA & 10423 & 10.423 & 387.47 & 2.588 \\
\hline & Water & IPA+water & 26.95 & 0.0269 & & \\
\hline \multirow{2}{*}{ Hexane-water } & Hexane & IPA & 97 & 0.097 & 3.818 & 0.581 \\
\hline & Water & IPA+water & 25.24 & 0.0254 & & \\
\hline \multirow[t]{2}{*}{ Oleyl alcohol-water } & Oleyl alcohol & IPA & 126 & 0.126 & 5.271 & 0.721 \\
\hline & Water & IPA+water & 23.21 & 0.0239 & & \\
\hline Dichloromethane-water & DCM & IPA & 17652 & 17.652 & 711.774 & 2.854 \\
\hline
\end{tabular}

IPA: Isopropyl alcohol, DCM: Dichloromethane

Table 4: Microscopic crystal shapes of docetaxel nanocrystal formulations

\begin{tabular}{|c|c|c|c|}
\hline Stabilizer & Formulation & Molar ratio & Crystal structure \\
\hline \multirow[t]{4}{*}{ Tween 80} & F1 & $1: 0.5$ & Large, rod, and elongated cylindrical \\
\hline & $\mathrm{F} 2$ & $1: 1$ & Small rods \\
\hline & F3 & $1: 3$ & Small rods \\
\hline & $\mathrm{F} 4$ & $1: 6$ & Small rods \\
\hline \multirow[t]{3}{*}{ Egg lecithin } & F5 & $1: 0.5$ & Large clusters \\
\hline & F6 & $1: 1$ & Irregular \\
\hline & F7 & $1: 3$ & Irregular \\
\hline \multirow[t]{4}{*}{ Povidone } & F9 & $1: 0.5$ & Large elongated cylindrical \\
\hline & F10 & $1: 1$ & Rod and cubic shaped \\
\hline & F11 & $1: 3$ & Rob shaped \\
\hline & F12 & $1: 6$ & Irregular \\
\hline \multirow[t]{4}{*}{ Tween 80 and PLGA } & F13 & $1: 1: 0.001$ & Irregular \\
\hline & F14 & $1: 1: 0.003$ & Physical unstable \\
\hline & F15 & $1: 1: 0.006$ & Physical unstable \\
\hline & F16 & $1: 1: 0.012$ & Physical unstable \\
\hline
\end{tabular}

PLGA: Poly (lactic-co-glycolic acid)

Table 5: Physicochemical characteristics of docetaxel nanocrystal formulations

\begin{tabular}{|c|c|c|c|c|c|}
\hline Stabilizer & Formulation & Molar ratio & Particle size (nm) & PDI & Zeta potential \\
\hline \multirow[t]{4}{*}{ Tween 80} & F1 & $1: 0.5$ & $240 \pm 39.76$ & $0.562 \pm 0.005$ & $-30.2 \pm 2.2$ \\
\hline & $\mathrm{F} 2$ & $1: 1$ & $142.9 \pm 29.28$ & $0.512 \pm 0.005$ & $-31.8 \pm 1.8$ \\
\hline & F3 & $1: 3$ & $138.4 \pm 36.12$ & $0.852 \pm 0.005$ & $-24.5 \pm 2.3$ \\
\hline & $\mathrm{F} 4$ & $1: 6$ & $133.4 \pm 27.16$ & $0.587 \pm 0.005$ & $-18.7 \pm 2.1$ \\
\hline \multirow[t]{3}{*}{ Egg lecithin } & F5 & $1: 0.5$ & $346.5 \pm 19.84$ & $0.756 \pm 0.005$ & $-31.5 \pm 1.8$ \\
\hline & F6 & $1: 1$ & $289.1 \pm 26.74$ & $0.542 \pm 0.005$ & $-32.6 \pm 1.6$ \\
\hline & F7 & $1: 3$ & $174.8 \pm 25.29$ & $0.489 \pm 0.005$ & $-34.6 \pm 2.5$ \\
\hline \multirow[t]{4}{*}{ PVP } & F9 & $1: 0.5$ & $362.7 \pm 14.37$ & $0.785 \pm 0.005$ & $-19.8 \pm 2.2$ \\
\hline & F10 & $1: 1$ & $161 \pm 33.36$ & $0.593 \pm 0.005$ & $-29.4 \pm 2.4$ \\
\hline & F11 & $1: 3$ & $153.2 \pm 31.12$ & $0.469 \pm 0.005$ & $-22.6 \pm 1.7$ \\
\hline & F12 & $1: 6$ & $144.5 \pm 26.56$ & $0.454 \pm 0.005$ & $-23.8 \pm 2.6$ \\
\hline \multirow[t]{4}{*}{ Tween 80 and PLGA } & F13 & $1: 1: 0.001$ & $81.0 \pm 19.89$ & $0.726 \pm 0.005$ & $-22.4 \pm 1.9$ \\
\hline & F14 & $1: 1: 0.003$ & $102.23 \pm 28.37$ & $0.534 \pm 0.005$ & $-23.72 \pm 1.9$ \\
\hline & F15 & $1: 1: 0.006$ & $93.56 \pm 24.16$ & $0.812 \pm 0.005$ & $-24.73 \pm 1.7$ \\
\hline & F16 & $1: 1: 0.012$ & $112.34 \pm 23.81$ & $0.413 \pm 0.005$ & $-24.93 \pm 2.5$ \\
\hline
\end{tabular}

All determinations were performed in triplicate and values were expressed as mean \pm SD, $(n=3)$. PDI: Polydispersity index, PVP: Polyvinyl pyrrolidine, SD: Standard deviation, PLGA: Poly (lactic-co-glycolic acid) 
series). Samples were backscattered by helium-neon laser (633 nm) at an angle of $90^{\circ}$ and at a constant temperature of $25^{\circ} \mathrm{C}$. Before the measurement, each sample was vortexed for $5 \mathrm{~s}$ to avoid particle settlement.

Zeta potential was estimated using the zetasizer (Horiba, nanopartica sz-100 series) which measures the particle electrophoretic mobility in a thermostated cell. All the samples were analyzed $24 \mathrm{~h}$ after their preparation.

Crystal morphology

Shape and surface morphology of nanoparticles were done by SEM; small volume of nanoparticulate suspension was placed on an electron

Table 6: Assay of formulations F2, F7, F10, and F13

\begin{tabular}{lll}
\hline Serial number & Formulation code & Assay (\%) \\
\hline 1 & F2 & $103.3 \pm 0.96$ \\
2 & F7 & $101.7 \pm 0.65$ \\
3 & F10 & $104 \pm 1.3$ \\
4 & F13 & $102 \pm 0.21$ \\
\hline
\end{tabular}

All determinations were performed in triplicate and values were expressed as mean \pm SD, $n=3$. SD: Standard deviation microscope brass stub. The stubs were placed briefly in a drier and then coated with gold in an ion sputter. Pictures of nanoparticles were taken by random scanning of the stub. The shape and surface morphology of the nanoparticles were determined from the photomicrographs of each batch.

\section{Docetaxel assay}

A standard and sample solution were prepared, inject separately $20 \mu \mathrm{l}$ of the standard and sample solution in chromatographic condition and record the chromatogram. Calculate the content of drug per $\mathrm{ml}$ in liposomal injection as follows:

$$
\text { Assay }=A_{\mathrm{s}} / A_{\mathrm{r}} \times C_{\mathrm{r}} / C_{\mathrm{s}} \times P
$$

Where,

$A_{\mathrm{s}}=$ Area corresponding to docetaxel peak in the sample

$A_{\mathrm{R}}=$ Area corresponding to docetaxel peak in the working standard

$C_{\mathrm{R}}=$ Concentration of docetaxel in working standard

$C_{\mathrm{S}}=$ Concentration of docetaxel in sample

$P=$ Percentage purity of working standard.

In vitro dissolution of docetaxel nanocrystals

The in vitro release of formulations carried out by membrane diffusion technique using dialysis sack of molecular weight cutoff

Table 7: Release rate profile of formulations F2, F7, F10, and F13

\begin{tabular}{|c|c|c|c|c|c|}
\hline \multirow[t]{2}{*}{ Formulation } & \multirow{2}{*}{$\begin{array}{l}\text { Zero order } \\
R^{2} \\
\end{array}$} & \multirow{2}{*}{$\begin{array}{l}\text { First order } \\
R^{2}\end{array}$} & \multirow{2}{*}{$\begin{array}{l}\text { Higuchi } \\
R^{2}\end{array}$} & \multicolumn{2}{|c|}{ Korsmeyer-Peppas } \\
\hline & & & & $R^{2}$ & $\mathbf{n}$ \\
\hline Tween 80 (F2) & 0.993 & 0.970 & 0.924 & 0.996 & 1.020 \\
\hline Egg lecithin (F7) & 0.849 & 0.984 & 0.998 & 0.975 & 1.031 \\
\hline PVP (F10) & 0.836 & 0.994 & 0.998 & 0.973 & 1.055 \\
\hline PLGA (F13) & 0.968 & 0.735 & 0.767 & 0.929 & 0.827 \\
\hline
\end{tabular}

*PVP: Polyvinyl pyrrolidine, PLGA: Poly (lactic-co-glycolic acid)

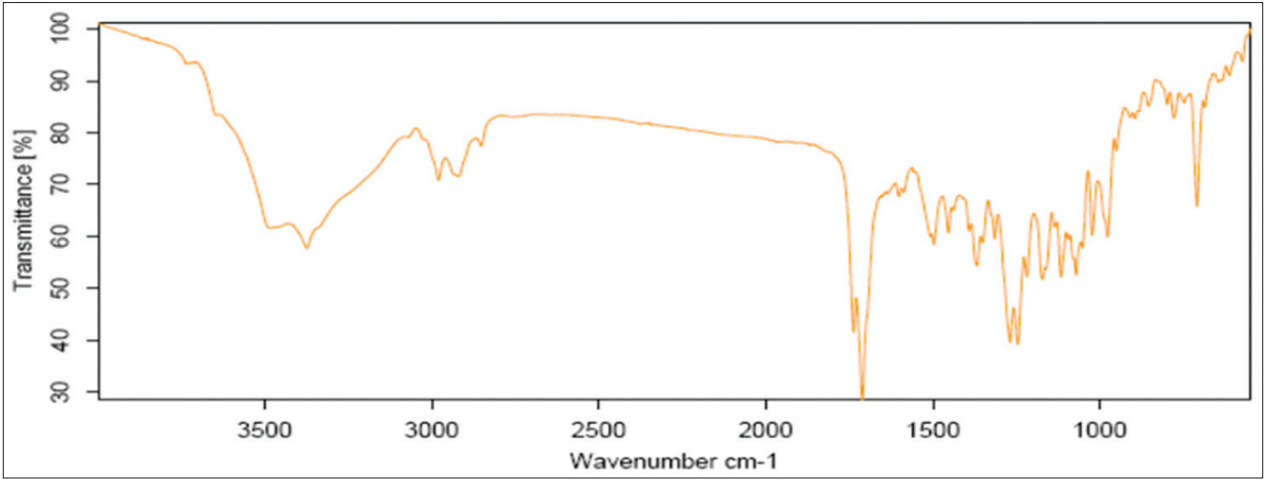

Fig. 2: Fourier-transform infrared spectroscopy spectrum of docetaxel

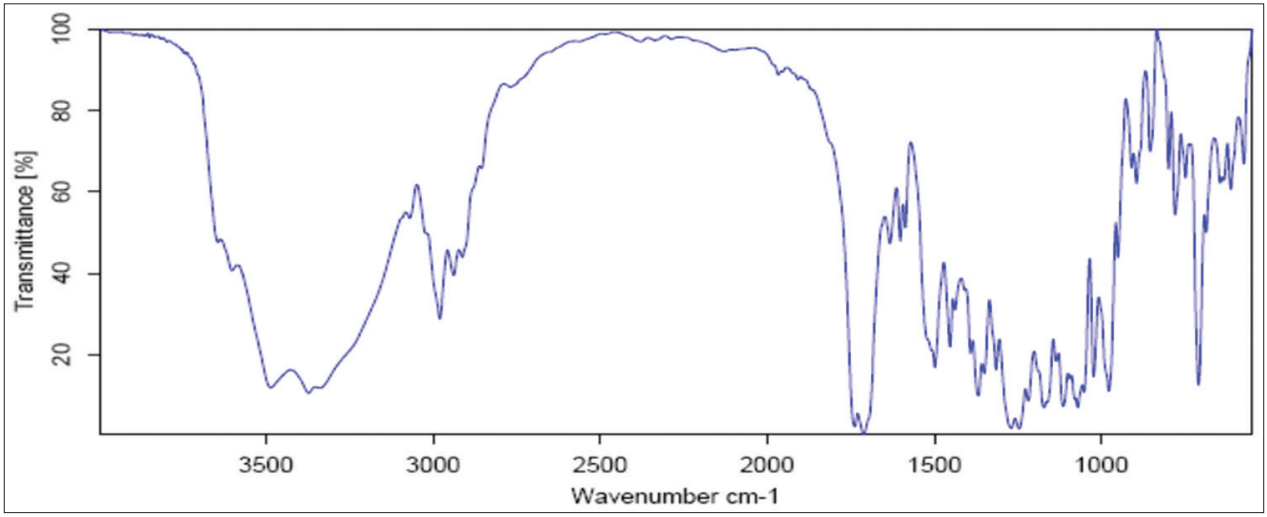

Fig. 3: Fourier-transform infrared spectroscopy spectrum of docetaxel and povidone physical mixture 
1000. Membrane was soaked in water for $30 \mathrm{~min}$ to remove traces of preservative and tied to one end of the glass test tube which constituted donor compartment. $2 \mathrm{ml}$ of the formulation was transferred to donor compartment and placed into receptor compartment of $400 \mathrm{~mL}$ of phosphate buffer with Tween 80 maintained at a temperature of $37^{\circ} \mathrm{C}$ and rotated at $300 \mathrm{rpm}$ using a magnetic stir bar. At specified time

\section{Table 8: Solubility profile of docetaxel nanocrystal optimized} formulations

\begin{tabular}{lll}
\hline Serial number & Formulation & Solubility $(\mu \mathrm{g} / \mathbf{m L})$ \\
\hline 1 & Pure drug & $12.777 \pm 1.65$ \\
2 & F2 & $54.444 \pm 3.12$ \\
3 & F7 & $49.536 \pm 2.42$ \\
4 & F10 & $52.114 \pm 2.38$ \\
5 & F13 & $51.346 \pm 2.89$ \\
\hline
\end{tabular}

All determinations were performed in triplicate and values were expressed as mean \pm SD, $n=3$. SD: Standard deviation

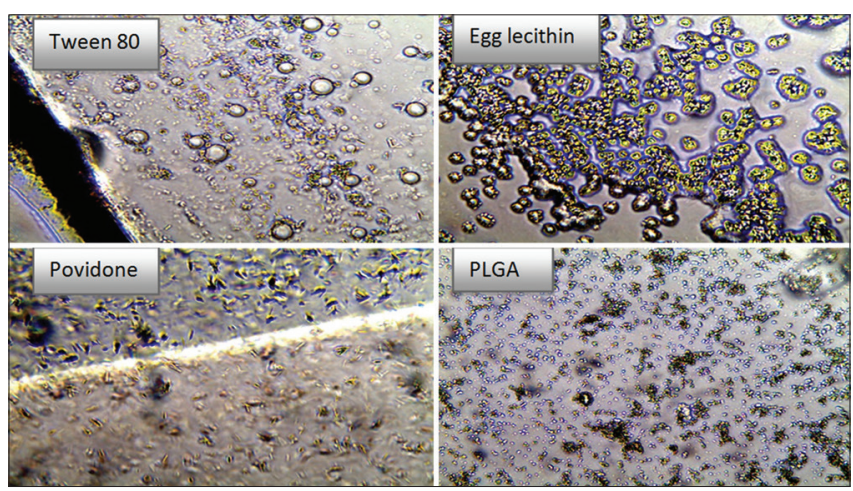

Fig. 4: Microscopic images of optimized formulations

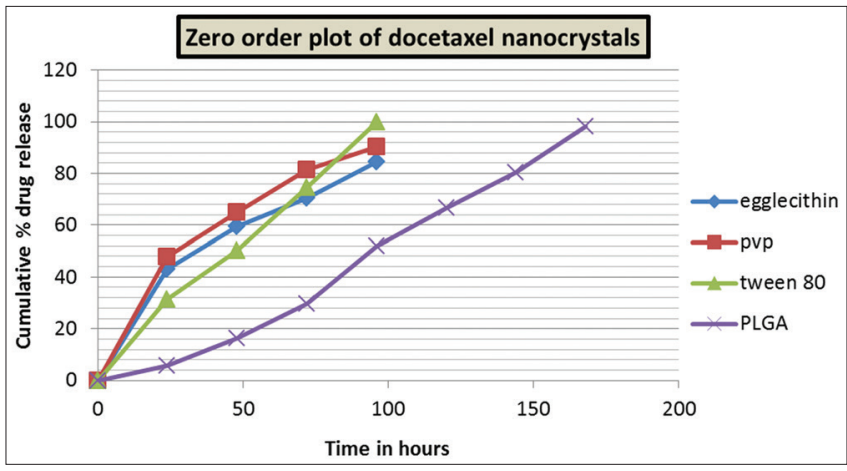

Fig. 5: Comparison of in vitro release studies for optimized formulations F2, F7, F10, and F13

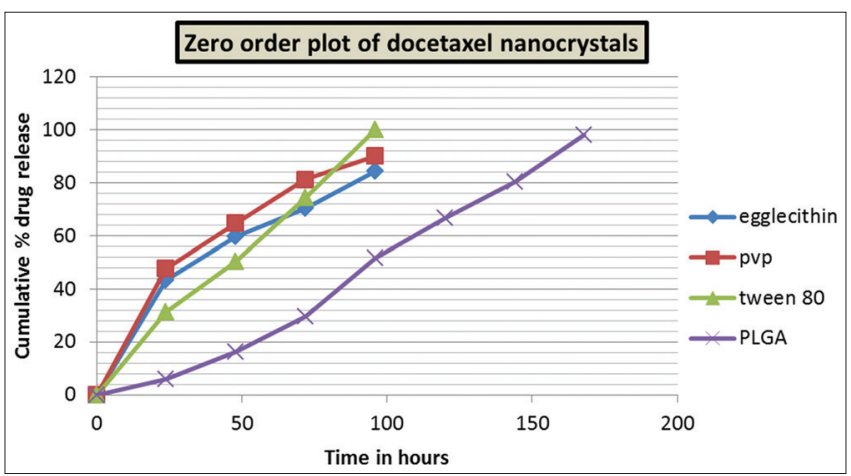

Fig. 6: Zero-order release studies for optimized formulations F2, F7, F10, and F13 points, the samples were withdrawn and replaced with fresh buffer immediately after sampling. These samples were filtered through $0.45 \mu \mathrm{m}$ membrane filter and analyzed spectrophotometrically at $231 \mathrm{~nm}$ after suitable dilution if necessary, using appropriate blank.

\section{Solubility studies}

Selected nanocrystal formulations solubility was determined in $\mathrm{pH} 7.4$ buffer. An excess amount of nanocrystal formulation was added into $50 \mathrm{ml}$ of the solvent. The mixture was stirred in a mechanical shaker for $24 \mathrm{~h}$. The mixture was then filtered and filtrate was diluted suitably to determine the solubility of drug.

\section{Stability studies}

The stability of a pharmaceutical delivery system may be defined as the capability of a particular formulation, in a specific container. The short-term stability was conducted to monitor physical and chemical

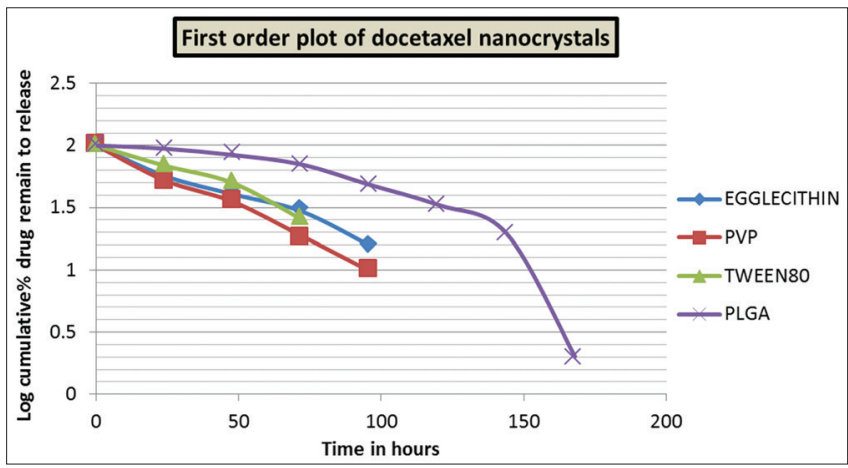

Fig. 7: First-order release studies for optimized formulations F2, F7, F10, and F13

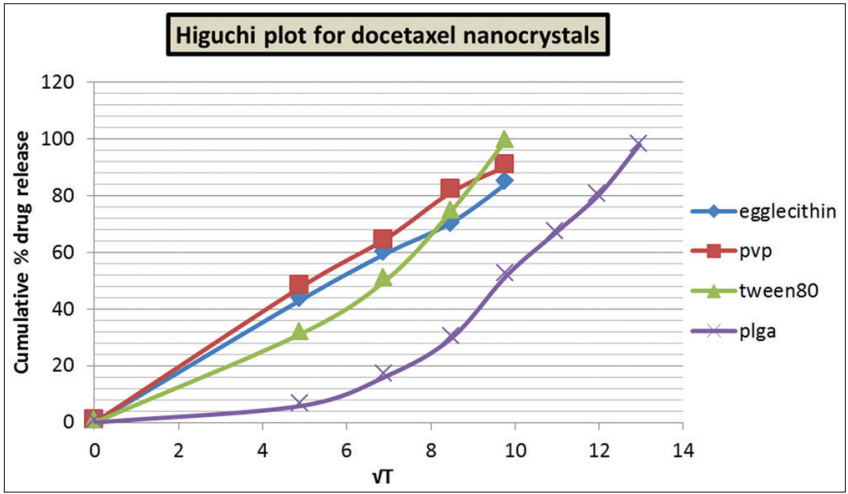

Fig. 8: Higuchi's order plot for optimized formulations F2, F7, F10, and F13

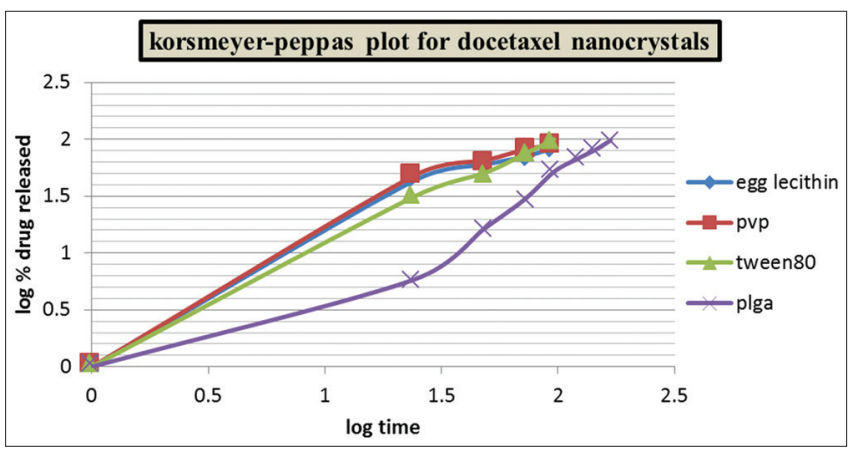

Fig. 9: Korsmeyer-Peppas model for optimized formulations F2, F7, F10, and F13 
Table 9: Stability data at $2-8^{\circ} \mathrm{C}$

\begin{tabular}{|c|c|c|c|c|c|c|}
\hline \multirow[t]{2}{*}{ Formulation code } & \multicolumn{6}{|c|}{ Time points (days) } \\
\hline & $0(\%)$ & $15(\%)$ & $30(\%)$ & $40(\%)$ & $60(\%)$ & $90(\%)$ \\
\hline F2 & $103.3 \pm 0.96$ & $102.1 \pm 0.73$ & $101.6 \pm 1.12$ & $100.8 \pm 0.43$ & $99.8 \pm 0.96$ & $98.5 \pm 0.96$ \\
\hline F7 & $101.7 \pm 0.65$ & $100 \pm 0.37$ & $99.1 \pm 0.12$ & $98.4 \pm 1.1$ & $98.1 \pm 0.65$ & $97.8 \pm 0.65$ \\
\hline F10 & $104 \pm 1.3$ & $101.5 \pm 1.0$ & $99.7 \pm 0.9$ & $99.2 \pm 0.63$ & $98.7 \pm 1.3$ & $97.7 \pm 1.7$ \\
\hline F13 & $102 \pm 0.21$ & $101.3 \pm 0.02$ & $100 \pm 1.23$ & $99.2 \pm 1.45$ & $99.1 \pm 0.28$ & $98.3 \pm 1.0$ \\
\hline
\end{tabular}

All determinations were performed in triplicate and values were expressed as mean $\pm S D, n=3$. SD: Standard deviation

Table 10: Stability data at $25^{\circ} \mathrm{C}$

\begin{tabular}{|c|c|c|c|c|c|c|}
\hline \multirow[t]{2}{*}{ Formulation code } & \multicolumn{6}{|c|}{ Time points (days) } \\
\hline & $0(\%)$ & $15(\%)$ & $30(\%)$ & $40(\%)$ & $60(\%)$ & $90(\%)$ \\
\hline $\mathrm{F} 2$ & $103.3 \pm 0.96$ & $101.8 \pm 0.33$ & $101 \pm 1.15$ & $100.1 \pm 0.83$ & $98.1 \pm 0.96$ & $96.1 \pm 0.16$ \\
\hline F10 & $104 \pm 1.3$ & $102.5 \pm 1.2$ & $100.7 \pm 0.4$ & $100.2 \pm 0.23$ & $99.5 \pm 1.7$ & $97.1 \pm 1.5$ \\
\hline F13 & $102 \pm 0.21$ & $102 \pm 0.11$ & $100.2 \pm 1.22$ & $99.2 \pm 0.93$ & $98.5 \pm 1.23$ & $97.1 \pm 0.23$ \\
\hline
\end{tabular}

All determinations were performed in triplicate and values were expressed as mean $\pm S D, n=3$. SD: Standard deviation

stabilities of the liquid form of docetaxel nanocrystal formulations at $25^{\circ} \mathrm{C} \pm 2{ }^{\circ} \mathrm{C}$ and $60 \% \pm 5 \% \mathrm{RH}$ for up to 3 months. The stability parameter, such as assay, was determined as function of the storage time.

\section{RESULTS AND DISCUSSION}

Standard curve of docetaxel in UV spectrophotometer

The UV absorbance of DTX standard solution is in the range of $10-40 \mu \mathrm{g} / \mathrm{ml}$ of drug in IPA and buffer $\mathrm{pH} 7.4$ (50:50) showed linearity at $\lambda \max 231 \mathrm{~nm}$. The linearity was plotted for absorbance against concentration with $\mathrm{R}^{2}$ value 0.999 and with the slope equation $\mathrm{y}=0.018 \mathrm{x}-0.006$. The standard curve of DTX is shown in Fig. 1.

\section{Compatibility studies}

The compatibility between the drug and excipients was evaluated using FTIR peak matching method. There was no appearance or disappearance of peaks in the drug-povidone mixture as evident from Figs. 2 and 3, which confirmed the absence of any chemical interaction between the drug and povidone. Compatibility of docetaxel with other ingredients was proved by stability studies.

\section{Partition coefficient}

The partition coefficient of paclitaxel was performed in different solvent systems and the results are shown in Table 3.

\section{Physicochemical characterization}

\section{Microscopic evaluation}

Different shaped crystals were observed in all the formulations as given in Table 4. In case of F14, F15, and F16 as the polymer concentration increases, the clarity of formulations was decreased, due to the increase in viscosity due to its high molecular weight. It was observed that the shape and size of the crystals were changed with the type and concentration of stabilizer [Fig. 4].

\section{Particle size and zeta potential}

The particle size distribution and zeta potential were analyzed for all formulations of DTX nanocrystals. In Tween 80 formulations, the optimum values were found in 1:1 ratio, in case of egg lecithin, it was $1: 3$ ratios, whereas in povidone, it was again 1:1 ratio, and in case of PLGA, it was 1:1:0.001 ratio. Particle size of all formulations was found to be in the nanometer range and a sufficiently high zeta potential value indicates that the formulations would be stable and the tendency to agglomerate would be miniscule [Table 5].
Assay

The assay value is determined for all the formulations. The assay value is within the limit $(90 \%-110 \%)$ for all the formulations, the results are shown in Table 6.

\section{In vitro dissolution data}

The in vitro dissolution profile of prepared formulations was determined by membrane diffusion method. The dissolution was carried out for a period of $168 \mathrm{~h}$ in $7.4 \mathrm{pH}$ phosphate buffer with 6\% Tween 80 .

The cumulative percent release of F2, F7, F10, and F13 formulations at various time intervals was calculated. The cumulative percent drug release in four formulations was plotted against time in Fig. 5. Cumulative percentage drug released for F2 after $96 \mathrm{~h}$ was more, i.e., $100 \%$, followed by F10 was $90.213 \%$ and for $\mathrm{F} 7$ was $84.312 \%$, whereas in case of F13, the cumulative percentage drug released after $96 \mathrm{~h}$ was only 51.799 and reached $97.987 \%$ after $168 \mathrm{~h}$. It was evident that the drug release from the F13 formulation decreased compared with the other three formulations. It was suggesting that the presence of polymer sustained the drug release.

\section{Release kinetics}

The release kinetics of F3, F6, and F9 formulations was studied. Based on the highest regression $\left[\mathrm{r}^{2}\right]$ values, the best-fit model for $\mathrm{F} 2$ and $\mathrm{F}$ 13 was zero order and for F7 and F10 was Higuchi diffusion model. All the formulations were then fitted into Korsmeyer-Peppas model and $\mathrm{n}$ values were reported. For F2, F7, and F10, it was $>1$ indicates super case-II transport and for F13, it was $<0.89$ indicates non-Fickian diffusion. The results are shown in Figs. 6-9 and Table 7.

\section{Solubility studies}

The solubility studies for pure drug and formulations were carried out in the PBS and the results are shown in Table 8. In four formulations, the solubility was increased 4 times when compared with the pure drug. This increased solubility can be attributed to enhanced dissolution of drug in nanocrystalline state.

\section{Stability data}

The stability of the docetaxel nanocrystals was evaluated after storage at $2-8^{\circ} \mathrm{C}$ and $25^{\circ} \mathrm{C}$ for 90 days. The assays of the samples were determined as a function of the storage time. The nanocrystals stored at $2-8^{\circ} \mathrm{C}$ were found to be stable for the duration of 90 days. The results are shown in Tables 9 and 10 . 


\section{CONCLUSION}

From the executed experimental results, it could be concluded that the Tween 80, egg lecithin, and povidone are the suitable stabilizers for the docetaxel nanocrystal formulation. The shape and size of the crystals were changed with the type and concentration of stabilizer. Addition of PLGA further reduces the particle size and sustained the drug release. Although the preliminary data based on in vitro dissolution profile, release kinetics and stability studies proved that the suitability of such formulations, still a thorough experiment will be required based on the animal studies. Thereafter, we can find the actual mode of action of this kind of dosage form.

\section{ACKNOWLEDGMENT}

We would like to thank Prof. K. VenuGopal Reddy (Director, Central Facilities for Research and Development, Osmania University, Hyderabad) for assistance with FTIR analysis.

\section{AUTHORS' CONTRIBUTIONS}

All the authors have contributed equally.

\section{COMPETING INTERESTS}

Declared none.

\section{REFERENCES}

1. Mousa SA, Bharali DJ. Nanotechnology-based detection and targeted therapy in cancer: Nano-bio paradigms and applications. Cancers (Basel) 2011;3:2888-903.

2. Shahira FE, Essam E, Adel AA, Ahmed AA. Enhancement of lornoxicam solubility by inclusion complexation with cyclodextrin: Preparation and characterization. Int J Pharm Pharm Sci 2017;9:132-8.

3. Bawa R. Nanoparticle-based therapeutics in humans: A survey. Nanotechnol Law Bus 2008;5:135-55.

4. Daraei B, Aghvami M, Pourahmad J, Dinarvand R. A comparison of hepatocyte cytotoxic mechanisms for docetaxel and PLGA-docetaxel nanoparticls. Iran J Pharm Res 2017;16:249-65.

5. Yared JA, Tkaczuk KH. Update on taxane development: New analogs and new formulations. Drug Des Devel Ther 2012;6:371-84.

6. Fauzee NJ. Taxanes: Promising anti-cancer drugs. Asian Pac J Cancer Prev 2011;12:837-51.

7. Velasco R, Bruna J. Taxane-induced peripheral neurotoxicity. Toxics 2015;3:152-69.

8. Matesanz R, Barasoain I, Yang CG, Wang L, Li X, de Inés C, et al. Optimization of taxane binding to microtubules: Binding affinity dissection and incremental construction of a high-affinity analog of paclitaxel. Chem Biol 2008;15:573-85.

9. Hart M, Acott S. Physical and chemical stability of taxotere (docetaxel) one-vial $(20 \mathrm{mg} / \mathrm{ml})$ infusion solution following refrigerated storage. Ecancermedicalscience 2010;4:202.

10. Qiu S, Liu Z, Hou L, Li Y, Wang J, Wang H, et al. Complement activation associated with polysorbate 80 in beagle dogs. Int Immunopharmacol 2013;15:144-9.

11. Varaporn BJ, Boontida M. Nanocrystals for enhancement of oral bioavailability of poorly water-soluble drugs. Asian J Pharm Sci
2015; 10:13-23.

12. Li Q, Cai T, Huang Y, Xia X, Cole SPC, Cai Y, et al. A review of the structure, preparation, and application of NLCs, PNPs, and PLNs. Nanomaterials (Basel) 2017;7:122.

13. Savjani KT, Gajjar AK, Savjani JK. Drug solubility: Importance and enhancement techniques. ISRN Pharm 2012;2012:195727.

14. Deng J, Huang L, Liu F. Understanding the structure and stability of paclitaxel nanocrystals. Int J Pharm 2010;390:242-9.

15. Mosallaei N, Jaafari MR, Hanafi-Bojd MY, Golmohammadzadeh S, Malaekeh-Nikouei B. Docetaxel-loaded solid lipid nanoparticles: Preparation, characterization, in vitro, and in vivo evaluations. J Pharm Sci 2013;102:1994-2004.

16. Athul PV. Preparation and characterization of simvastatin nanosuspension By homogenization method. Int J Pharm Tech Res 2013;5:193-7

17. Anita PP, Patel JK, Kishubu SP. A review on drug nanocrystal a carrier free drug delivery. Int J Res Ayurveda Pharm 2011;2:448-58.

18. Tuomela A, Hirvonen J, Peltonen L. Stabilizing agents for drug nanocrystals: Effect on bioavailability. Pharmaceutics 2016;8:E16.

19. Sun J, Wang F, Sui Y, She Z, Zhai W, Wang C, et al. Effect of particle size on solubility, dissolution rate, and oral bioavailability: Evaluation using coenzyme $\mathrm{Q}_{10}$ as naked nanocrystals. Int J Nanomedicine 2012;7:5733-44.

20. Hanafy A, Spahn-Langguth H, Vergnault G, Grenier P, Tubic Grozdanis M, Lenhardt T, et al. Pharmacokinetic evaluation of oral fenofibrate nanosuspensions and SLN in comparison to conventional suspensions of micronized drug. Adv Drug Deliv Rev 2007;59:419-26.

21. Gao L, Zhang D, Chen M, Duan C, Dai W, Jia L, et al. Studies on pharmacokinetics and tissue distribution of oridonin nanosuspensions. Int J Pharm 2008;355:321-7.

22. Ali HS, York P, Ali AM, Blagden N. Hydrocortisone nanosuspensions for ophthalmic delivery: A comparative study between microfluidic nanoprecipitation and wet milling. J Control Release 2011;149:175-81.

23. El-Gendy N, Pornputtapitak W, Berkland C. Nanoparticle agglomerates of fluticasone propionate in combination with albuterol sulfate as dry powder aerosols. Eur J Pharm Sci 2011;44:522-33.

24. Mitri K, Shegokar R, Gohla S, Anselmi C, Müller RH. Lutein nanocrystals as antioxidant formulation for oral and dermal delivery. Int J Pharm 2011;420:141-6.

25. Müller RH, Jacobs C. Buparvaquone mucoadhesive nanosuspension: Preparation, optimisation and long-term stability. Int $\mathrm{J}$ Pharm 2002;237:151-61.

26. Anju G, Rupa M, Kamla P. Formulation, optimization and characterization of ziprasidone nanocrystals prepared by media milling technique. Int J Pharm Pharm Sci 2015;7:146-50.

27. Vidyavathi M, Sandya P, Sarika B. Nanotechnology in development of drug delivery system. Int J Pharm Sci Res 2012;3:84-96.

28. Bosselmann S, Nagao M, Chow KT, Williams RO $3^{\text {rd }}$. Influence of formulation and processing variables on properties of itraconazole nanoparticles made by advanced evaporative precipitation into aqueous solution. AAPS PharmSciTech 2012;13:949-60.

29. Kakran M, Shegokar R, Sahoo NG, Gohla S, Li L, Müller RH, et al. Long-term stability of quercetin nanocrystals prepared by different methods. J Pharm Pharmacol 2012;64:1394-402.

30. Alessandra V, Jean J, Espitalier F, Mariaines R, Vicosa A. An innovative antisolvent precipitation process as a promising technique to prepare ultrafine rifampicin particles. J Cryst Growth 2012;342:80-7.

31. Basavaraj KN, Ganesh KD, Hiren MB, Veerendra KN, Manvi FV. Design and characterization of nanocrystals of lovastatin for solubility and dissolution enhancement. J Nanomed Nanotechnol 2011;2:1-7. 